\title{
Prevalence of urinary tract infection in children in the kingdom of Saudi Arabia
}

\author{
Mariam Alrasheedy ${ }^{1}$, Hoda Jehad Abousada ${ }^{2}$, Mutaz Mansour Abdulhaq ${ }^{3}$, Raghad Abdulelah Alsayed ${ }^{4}$, \\ Khalid Abdullah Alghamdi ${ }^{5}$, Fayez Dhyefallah Alghamdi ${ }^{5}$, Abdullah Faisal Al Muaibid ${ }^{5}$, \\ Refal Ghassan Ajjaj ${ }^{6}$, Seham Salem Almohammadi ${ }^{7}$, Sarah Salem Almohammadi ${ }^{7}$, Wajd Adnan Alfitni ${ }^{8}$, \\ Abdulrahman Mohamed Homsi ${ }^{9}$, Meqbel Majed Alshelawi ${ }^{10}$, Hassan Ali Alshamrani ${ }^{11}$, Abdulrauf \\ Abdulatif Tashkandi ${ }^{11}$, Sara Mohammed Mannan ${ }^{12}$, Salihah Attiah Alsamiri ${ }^{13}$ \\ ${ }^{1}$ Pediatric Nephrology, East Jeddah Hospital, KSA; \\ 2 Obstetrics \& Gynecology Physician, KAMC, KSA; \\ ${ }^{3}$ East Jeddah Hospital, KSA; \\ ${ }^{4}$ Ohod Hospital, Madinah, KSA; \\ ${ }^{5}$ Baha University, Baha, KSA; \\ ${ }^{6}$ ISNC, Jeddah, KSA; \\ ${ }^{7} \mathrm{KFH}$, Jeddah, KSA; \\ ${ }^{8}$ Batterjee Medical College, Jeddah, KSA; \\ ${ }^{9}$ Uqu University, Mecca, KSA; \\ ${ }^{10}$ Medical University of Silesia, Katowice, Poland; \\ ${ }^{11}$ Taif University, Taif, KSA; \\ 12 King Abdulaziz University, Jeddah, KSA; \\ ${ }^{13}$ RCSI, Dublin, Ireland.
}

\section{Summary} is a common disorder in childhood. Early identification and appropriate antibiotic use are essential to avoid long-term sequels. The trial objective was to identify the prevalence of URI in children, and the risk factors.

Methods: This is an analytical cross-sectional study conducted in the Saudi Arabia, from April $4^{\text {th }} 2020$ till July $30^{\text {th }} 2020$.

The sample was randomly selected from children who presented to the ministry of health tertiary hospitals. People answered a questionnaire of 10 items.

Results: 1083 people participated in the current trial.

The prevalence of UTI was $25.8 \%$. The mean age was 4.5-5

years. UTI was commoner in females than males. Urethritis was the main presenting complaint. Western region was the commonest identified area. Those with multivitamin deficiency had the highest prevalence.

Conclusion: UTI is not a very common problem for children in Saudi Arabia. Western region had the highest prevalence and the peak age ranged from 4.5 to 5 years. Additionally, nearly a sixth of children could develop severe/complicated UTI.

KEY WORDS: Urinary tract infection; Saudi; Pyelonephritis; Cystitis; Urethritis.

Submitted 18 November 2020; Accepted 1 December 2020

\section{INTRODUCTION}

Urinary tract infection (UTI) is a common clinical problem in childhood $(1,2)$. Internationally, it is anticipated that 150 million UTI cases occur annually, and it costs more than 6 billion dollars, yearly. The prevalence of UTI ranges from $6 \%$ in more developed countries to
$37 \%$ in developing countries with a prevalence rate of nearly $8 \%$ in USA $(3,4)$.

Prior trials have assessed the incidence of UTI in other developing countries. In Nigeria, the prevalence of UTI is $11 \%$, and it is $12 \%$ in India, $6 \%$ in Kenya and 20\% in South Africa. Saudi Arabia has a different ethnic and diverse population. Apart from Saudi citizens, it has Egyptians, Syrians, Yemeni, Indians, Pakistani, Bangladeshi, and Philippians. The study of Alanazi et al. estimated the prevalence of UTI in Saudi Arabia at 24\% (5-10).

Risk factors associated with UTI include child age, lack of circumcision, urinary obstructive conditions, such as, hydronephrosis, posterior urethral valve occlusion, ureteropelvic junction obstruction, neurological conditions including myelomeningocele with neurogenic bladder, bladder and bowel dysfunction, vesicoureteral reflux (VUR), renal scarring, and/or bladder catheterization. Also, the prevalence increases in children with malnutrition. Online calculators have developed to estimate the risk for UTI, such as, the calculator from the University of Pittsburgh (3, 11-14).

Escherichia coli is the commonest pathogen in paediatric UTI and it causes 70\% of infections. Other pathogens include Proteus, Klebsiella, Enterococcus, Citrobacter, and Pseudomonas aeruginosa $(5,11)$.

UTI manifests as either pyelonephritis which tends to present with fever and loin pain. Cystitis and urethritis usually present with urine soreness and increased frequency. It is difficult to distinguish pyelonephritis from cystitis in children below the age of two (3).

Early identification and appropriate antibiotic use are essential to avoid the long-term sequels of UTI including 
kidney scarring, chronic renal impairment and hypertension. On the other hand, the inappropriate use of antibiotics is one of the major reasons for antimicrobial resistance which represents a serious global problem. This is because it causes significant impacts on health-care costs, and patient morbidity, and mortality $(15,16)$.

The current trial main objective is to identify the prevalence of UTI in children in Saudi Arabia. Also, the research aims to know the risk factors for UTI including the region with the highest prevalence, the most common types of presentation, and the risk factors for the development of UTI.

\section{Patients AND Methods}

\section{Study design and setting}

This is an analytical cross-sectional study which was carried out in the period between April $4^{\text {th }} 2020$ and July $30^{\text {th }} 2020$ in the ministry of health hospitals in the kingdom of Saudi Arabia.

\section{Study population}

The sample was randomly selected, through the computer, from children who presented to both general inpatient and outpatient departments in the ministry of health tertiary hospitals between April $4^{\text {th }} 2020$ and July $30^{\text {th }} 2020$.

The authors aimed to contact 1600 families. Selection was done by the computer to ensure that the selected sample was accurately representing the population in terms of their age, gender, and residency region. For inclusion in the current study, the surveyed sample should be either citizens or residents in the country with their family. To avoid including cases with hospital acquired UTI, for inpatients, the authors included only patients up to 2 days of their admission.

People answered a survey of 10 items about their residency region (Eastern, Western, Central, Southern, or Northern); if they have a child who developed urinary tract infection; the age of that child when having UTI; the gender of the child; the type of presentation; if the child had a risk factor including hydronephrosis, diabetes mellitus, autism, congenital abnormalities, diseases of the immune system, or vitamin deficiency; if the child was hospitalised because of UTI, people's definition for UTI; whether UTI recurred within a period of one month after the first diagnosis. Finally, the survey asked about the person who answered the questionnaires (Father or Mother).

People who fit with the inclusion criteria of the study were included in the current trial. Additionally, the criteria included age of children between 1 and 10 years. Collection dates were from April $4^{\text {th }}, 2020$, to June $30^{\text {th }}$. 2020.

\section{Study measurements}

The prevalence of UTI was defined as the proportion of children with the target disease among all the number of children. The current study examined the link between UTI and certain predefined factors including the region of residency, age, gender, and other comorbidities.

Also, severe/complicated UTI was defined as that which required hospitalisation, presented with pyelonephritis, or recurrent UTI within 30 days after the initial diagnosis (17).

\section{Statistical analysis}

Statistical analysis was carried out by Statistical Package for the Social Sciences (SPSS) version 17. Continuous data were presented in terms of mean, median, mode and 95\% Confidence interval (CI). Univariate analysis with OR using Chi-squared test and Mann-Whitney test was performed to investigate the association between UTI, severe/complicated UTI and predefined factors including their region of residency, age, gender, and comorbidities. Multivariate analysis with HR was performed using binary logistic regression. P-value was set at a significance level of $<0.05$.

\section{Ethical consideration}

Ethical approval was sought from the biomedical ethics research committee of the faculty of medicine, ministry of health, Kingdom of Saudi Arabia.

Prospective informed consent was taken from all participants. The authors confirmed that they did not receive any funding from agencies in the public, commercial, or not-for-profit sectors.

Table 1.

Sample characteristics.

\begin{tabular}{|ll|c|c|c|}
\hline & & Number & Percentage \% & P-value \\
\hline Age: (years) & $1-3$ & 249 & 23 & 0.06 \\
& $3.1-6$ & 401 & 37 & \\
& $6.1-8$ & 103 & 9.5 & \\
& $8.1-10$ & 217 & 20 & \\
& Unknown & 113 & 10.5 & \\
Mean & & $4.5-5$ years & & \\
$95 \% \mathrm{Cl}$ & & $1-10$ years & & 0.05 \\
\hline Gender: & Male & 454 & 41.9 & \\
& Female & 629 & 58.1 & 0.04 \\
\hline Region: & Western & 417 & 38.5 & \\
& Eastern & 343 & 31.7 & \\
& Central & 105 & 9.7 & \\
& Northern & 36 & 3.3 & \\
& Southern & 182 & 16.8 & \\
\hline
\end{tabular}

Table 2.

Patient's characteristics.

\begin{tabular}{|cl|c|c|c|}
\hline & & Number & Percentage \% & P-value \\
\hline Age: (years) & $1-3$ & 64 & $23 \%$ & 0.06 \\
& $3.1-6$ & 101 & $36 \%$ & \\
& $6.1-8$ & 27 & $9.7 \%$ & \\
& $8.1-10$ & 57 & $20.5 \%$ & \\
& Unknown & 30 & $10.8 \%$ & \\
& Mean & $4.5-5$ years & & \\
& $95 \%$ Cl & $1-10$ years & & \\
\hline Gender: & Male & 118 & 42 & 0.05 \\
& Female & 162 & 58 & \\
\hline Region: & Western & 109 & 39 & 0.04 \\
& Eastern & 90 & 32 & \\
& Central & 15 & 5.4 & \\
& Northern & 25 & 8.9 & \\
& Southern & 41 & 14.7 & \\
& Mean & Western & & \\
& & & & \\
\hline
\end{tabular}


Figure 1.

The frequency of surveyors who responded to the question "How to define UTI".

\begin{tabular}{|c|c|c|c|c|c|}
\hline \multicolumn{6}{|c|}{ What do you think is the correct definition for urinary tract infection? } \\
\hline & & Frequency & Percent & Valid percent & Cumulative percen \\
\hline Valid & $\begin{array}{l}\text { An infection of the kidney, } \\
\text { ureter, bladder, or urethra }\end{array}$ & 540 & 49.9 & 49.9 & 49.9 \\
\hline & An infection of the kidney only & 31 & 2.9 & 2.9 & 52.7 \\
\hline & An infection of the ureter only & 34 & 3.1 & 3.1 & 55.9 \\
\hline & $\begin{array}{l}\text { An infection of the bladder, } \\
\text { or urethra only }\end{array}$ & 478 & 44.1 & 44.1 & 100.0 \\
\hline & Total & 108.3 & 100.0 & 100.0 & \\
\hline
\end{tabular}

\section{RESULTS}

One thousand six- hundred people were contacted and the authors got responses from 1083 of them. 280 people stated that their child had UTI, and the prevalence of UTI in the sample was $25.8 \%$. Tables 1 and 2 summarised the sample characteristics and patient characteristics.

One hundred and thirty-one (47\%) children presented

Table 3.

Univariate analysis for UTI.

\begin{tabular}{|l|c|c|c|c|}
\hline Factor & UTI & No UTI & OR (95\% CI) & P-value \\
\hline Agge 1-6 years & 165 & 485 & $0.00(0.00-2.00)$ & 0.04 \\
Agge 6.1-10 & 84 & 320 & $0.035(0.02-2.2)$ & 0.05 \\
Regions Western, and Eastern & 199 & 561 & $0.02(0.00-2.00)$ & 0.04 \\
Other regions & 81 & 242 & $0.04(0.02-2.1)$ & 0.05 \\
Male & 118 & 336 & $0.04(0.02-2.2)$ & 0.06 \\
Female & 162 & 467 & $0.03(0.02-2.0)$ & 0.05 \\
Comorbidities & 54 & 31 & $1.1(1.00-2.3)$ & 0.04 \\
\hline
\end{tabular}

Table 4.

Univariate analysis for severe/complicated UTI.

\begin{tabular}{|l|c|c|c|c|}
\hline Factor & UTI & No UTI & OR (95\% CI) & P-value \\
\hline Agge 1-6 years & 30 & 620 & $0.00(0.00-2.00)$ & 0.03 \\
Agge 6.1-10 & 21 & 383 & $0.03(0.02-2.1)$ & 0.05 \\
Regions Western, and Eastern & 35 & 725 & $0.03(0.02-2.00)$ & 0.04 \\
Other regions & 16 & 307 & $0.04(0.03-2.1)$ & 0.03 \\
Male & 20 & 434 & $0.05(0.03-2.1)$ & 0.04 \\
Female & 31 & 598 & $0.04(0.02-2.0)$ & 0.06 \\
Comorbidities & 31 & 53 & $1.05(1.0-2.8)$ & 0.05 \\
\hline
\end{tabular}

Table 5.

Multivariate analysis for UTI.

\begin{tabular}{|l|c|c|}
\hline Factor & HR $\mathbf{( 9 5 \%} \mathbf{~ C l )}$ & P-value \\
\hline Age 1-6 years & $0.5(0.09-1.00)$ & 0.03 \\
Regions Western, and Eastern & $0.7(0.5-1.1)$ & 0.04 \\
Male & $1.3(0.9-2.1)$ & 0.06 \\
Comorbidities & $1.1(0.9-2.0)$ & 0.05 \\
\hline
\end{tabular}

Table 6.

Multivarte analysis for Severe/complicated UTI.

\begin{tabular}{|l|c|c|}
\hline Factor & HR $(95 \%$ Cl) & P-value \\
\hline Age 1-6 years & $0.6(0.1-1.00)$ & 0.03 \\
Regions Western, and Eastern & $0.6(0.4-1.0)$ & 0.04 \\
Male & $1.4(1.1-2.1)$ & 0.04 \\
Comorbidities & $1.1(0.8-2.0)$ & 0.05 \\
\hline
\end{tabular}

with urethritis, 93 (33\%) children had cystitis, 28 (10\%) children had pyelonephritis, and for the remaining 28 (10\%) children location of infection was unknown. Seven (2.2\%) children had hydronephrosis; 16 (5.8\%) children had diabetes mellitus; one $(0.4 \%)$ child had autism; three (1.1\%) children had congenital abnormalities; three (1.1\%) children immune disorders; 24 (8.6\%) children had a vitamin deficiency; the remaining 226 (80.8\%) had no comorbidities. As shown in Figure 1, $540(49.9 \%)$ of the responders defined UTI as infection in the kidneys, ureter, urethra, or urinary bladder; 478 (44.1\%) of the sample defined UTI as infection in the urethra or urinary bladder; 31 (2.9\%) of people defined UTI as infection in the kidneys only; 34 (3.1\%) of people defined it as infection in the urethra only.

Twenty-eight $(10 \%)$ of patients required admission for their UTI, and 24 (8.5\%) of patients developed recurrent UTI within 30 days of their initial UTI. Accordingly, 51 (18\%) of children with UTI developed severe/complicated UTI. To note, eight patients had recurrent UTI and they did not require admission, so they did not meet the current criteria for severe/complicated UTI. Tables 3 and 4 showed univariate analysis for UTI and severe/complicated UTI, respectively. Multivariate analysis for UTI and severe/complicated are shown in Tables 5 and 6 respectively. Finally, $54.5 \%$ of questionnaires were answered by mothers and the rest was answered by fathers.

\section{Discussions}

The current study aims to identify the prevalence of urinary tract infection (UTI) in children in the kingdom of Saudi Arabia and the risk factors for UTI. The authors believe that the health of children has always been the health of future generations. Children are more susceptible to UTI than other age groups. Perhaps this is related to their low immunity, lack of family attention to their child hygiene and malnutrition. Saudi Arabia has a diverse ethnic population, and it depends on two sources of water, which are groundwater and water from desalination plants which remove salt from seawater. Also, serum vitamin D level is low among $40 \%$ of the Saudi population. Knowing the prevalence of the disease and identifying the risk group could help physicians in selecting patients who benefit from an additional diagnostic test and prioritise patients who require an additional care $(18,19)$.

The current study is a cross-sectional study that was based on interviewing families of children who presented to the outpatient department and inpatient wards in the tertiary ministry of health hospitals over 3-month period. The tertiary ministry of health hospitals represents $81 \%$ of health care services in the country and represents the well-established care level for patients.

The authors decided to conduct a cross-sectional survey which evaluates the prevalence of certain diseases and their risk factors at the same point in time. Cross-sectional survey provides the best way to identify a disease and its risk factors in a predefined population $(20,21)$. Previous research was conducted in the area of paediatric UTI in Saudi Arabia.

The study of Garout et al. (22) investigated the preva- 
lence of UTI in Riyadh, the research conducted by AlIbrahim et al. (23) studied the prevalence of UTI in a tertiary hospital in Riyadh over a 3-year period, the study of Al-Otaibi and Bukhari (24) investigated the incidence of hospital-acquired UTI in a hospital in Riyadh and Alanazi (25) evaluated the prevalence of UTI in emergency departments amongst adults, elderly and children. However, until the time of publication, there has not been any available data stratifying UTI prevalence based on gender, age, region, or comorbidities, and to the knowledge of the authors, this was the first study that examined the prevalence of UTI on a wide scale of people across the country. The current study focused on community-acquired UTI which is a major problem worldwide. Also, it included 1083 responders who fit with its inclusion criteria (22-25).

The current study showed the prevalence of UTI of $25.8 \%$ in children aged 1 to 10 years. The study of Alanazi et al. (25) showed comparable results. Similarly, the study of Shisana et al. (10) showed the prevalence of UTI in South Africa at 20\%. Other trials showed different rates about $8 \%$. The prevalence of UTI varies widely among countries and in different regions in the same country, due to many factors including age, gender, socioeconomic status and health condition $(6,10,23)$. This trial showed that the prevalence of UTI varied widely by age, gender and regional place and comorbidities. The mean age of UTI was 4.5-5 years. The study of Garout et al. (22) showed a mean age of incidence of 5 years. The difference could be related to the majority of cases in the latter trial coming from the central region rather than the Western area as in the current trial. Also, UTI was more common among females. The study of Garout (22) agreed with our findings. The main presenting complaint was urethritis. The study of Alanazi (25) showed a similar finding.

Those with vitamin deficiency as comorbidity had the highest prevalence. Wald (26) agreed with the current finding as the author mentioned that low vitamin levels, including low vitamin D, increased the risk for UTI.

The current trial revealed that western region had the highest prevalence rate. This is probably related to the fact that the Western region had the highest number of participants in the current trial. Also, the majority of responders did not have any comorbidity. Additionally, the majority of respondents selected the correct definition for urinary tract infection. Moreover, nearly a sixth of children developed severe UTI.

This is the first trial that addresses these observations, but further trials are required to confirm the current findings.

The current trial defined severe/complicated UTI as UTI which requires admission, recurrent UTI within 30 days, and UTI presenting with pyelonephritis. The study of Colgan and Mozella (27) agreed with these definitions in adult population, although there is not any clear definition for severe UTI in paediatric population. The authors believe that there should be a consensus among physicians about the definition of complicated/severe UTI in childhood.

The current study has some limitations. It was conducted amongst patients who visited the ministry of health hospi- tals which provide the majority of health services in the country. Further research is required to cover patients who visit community services and private hospitals. Also, the current study was conducted over a 4-month period. Further research is required with a longer duration to confirm the current study results.

\section{Conclusions}

Urinary tract infection (UTI) is not very common for children in the Kingdom of Saudi Arabia. Western region had the highest disease prevalence and the peak age for UTI ranged from 4.5 to 5 years. The most common presenting symptom was urethritis and almost a sixth of children developed severe/complicated UTI.

\section{REFERENCES}

1. Subcommittee on Urinary Tract Infection, Steering Committee on Quality Improvement and Management, Roberts KB. Urinary tract infection: clinical practice guideline for the diagnosis and management of the initial UTI in febrile infants and children 2 to 24 months. Paediatrics. 2011; 128:595-610.

2. National Institute for Health and Clinical Excellence. Urinary Tract Infection in Children. London (UK): NICE; 2007.

3. Shaikh N, Morone NE, Bost JE, Farrell MH. Prevalence of urinary tract infection in childhood: a meta-analysis. Pediatr Infect Dis J. 2008; 27:302-308.

4. Foxman B. Urinary tract infection syndromes: occurrence, recurrence, bacteriology, risk factors, and disease burden. Infect Dis Clin North Am. 2014; 28:1-13.

5. The total population in 2018. general authority for statistics (Saudi Arabia). Archived from the original on 2019-04-03.

6. Alanazi MQ, Al-Jeraisy MI, Salam M. Prevalence and predictors of antibiotic prescription errors in an emergency department, Central Saudi Arabia. Drug Healthc Patient Saf. 2015; 7:103-111.

7. Ghorashi Z, Ghorashi S, Soltani-Ahari H, Nezami N. Demographic features and antibiotic resistance among children hospitalized for urinary tract infection in northwest Iran. Infect Drug Resist. 2011; 4:171-176.

8. Rabasa AI, Shattima D. Urinary tract infection in severely malnourished children at the University of Maiduguri Teaching Hospital. J Trop Pediatr. 2002; 48:359-361.

9. Kala UK, Jacobs DW. Evaluation of urinary tract infection in malnourished black children. Ann Trop Paediatr. 1992; 12:75-81.

10. Shisana O, Rehle T, Simbayi LC, et al. South African National HIV Prevalence, Incidence and Behaviour Survey, 2014. Cape Town, South Africa: HSRC Press; 2014.

11. Alshamsan L, Al Harbi A, Fakeeh K. The value of renal ultrasound in children with a first episode of urinary tract infection. Ann Saudi Med. 2009; 29:46-49.

12. Shaw KN, Gorelick M, McGowan KL, et al. Prevalence of urinary tract infection in febrile young children in the emergency department. Pediatrics. 1998; 102:e16.

13. Singh-Grewal D, Macdessi J, Craig J. Circumcision for the prevention of urinary tract infection in boys: a systematic review of randomised trials and observational studies. Arch Dis Child. 2005; 90:853. 
14. Wald ER. Cystitis and pyelonephritis. In: Feigin and Cherry's Textbook of Pediatric Infectious Diseases, $8^{\text {th }}$ ed, Cherry JD, Harrison G, Kaplan SL, et al. (Eds), Elsevier, Philadelphia 2018. p.395.

15. Shim YH, Lee JW, Lee SJ. The risk factors of recurrent urinary tract infection in infants with normal urinary systems. Pediatr Nephrol. 2009; 24:309.

16. Caksen H, Cesur Y, Uner A, et al. Urinary tract infection and antibiotic susceptibility in malnourished children. Int J Urol Nephrol. 2000; 32:245-247.

17. Haynes RB, Sackett DL, Guyatt GH, Tugwell P. Clinical Epidemiology: How to Do Clinical Practice Research. $3^{\text {rd }}$ ed. Philadelphia, PA: Lippincott Williams \& Wilkins, 2006.

18. Abderrahman WA Water Management in ArRiyadh, International Journal of Water Resources Development 2006; 22:277-289.

19. Amer Kamel, et al., editors. The Water, Energy, and Food Security Nexus in the Arab Region. $1^{\text {st }}$ ed., ser. 2017, 2367-4008, Springer International Publishing.

20. Health Indicators, Ministry of Health, Department of Statistics, 2006.
21. Schmidt CO, Kohlmann, T. When to use the odds ratio or the relative risk? Int J Public Health. 2008; 53:165-7.

22. Garout WA, Kurdi HS, Shilli AH, and Kari JA. Urinary tract infection in children younger than 5 years. Saudi Med J. 2015; 36:497-501.

23. Al-Ibrahim AA, Girdharilal RD, Jalal MA, et al. Urinary tract infection and vesicoureteral reflux in Saudi children. Saudi J Kidney Dis Transpl. 2002; 13:24-28.

24. Al-Otaibi FE, Bukhari EE. Clinical and laboratory profiles of urinary tract infections caused by extended-spectrum beta-lactamase-producing Escherichia coli in a tertiary care center in central Saudi Arabia. Saudi Med J. 2013; 34:171-176.

25. Alanazi MQ. An evaluation of community-acquired urinary tract infection and appropriateness of treatment in an emergency department in Saudi Arabia. Ther Clin Risk Manag. 2018; 14:2363-2373.

26. Wald ER. Cystitis and pyelonephritis. In: Feigin RD, Cherry J, Demmler-Harrison GL, Kaplan SL, editors. Feigin and Cherry's text book of infectious diseases. $6^{\text {th }} \mathrm{ed}$. Philadelphia (PA): Elsevier Saunders; 2009, pp. 554-569.

27. Colgan R, Mozella WM. Diagnosis and treatment of acute pyelonephritis in women. Am Fam Physician. 2011; 84:519-526.

\section{Correspondence}

Mariam Alrasheedy, MD

ma-rasheedy@moh.gov.sa

Consultant Pediatric nephrology, East Jeddah Hospital (KSA)

Hoda Jehad Abousada, MD (Corresponding Author)

dr.huda1992@outlook.com

Obstetrics \& Gynecology Physician, KAMC (KSA)

Mutaz Mansour Abdulhaq, MD

Pediatric Resident, East Jeddah Hospital (KSA)

Raghad Abdulelah Alsayed, MD

raghadalsayed148@gmail.com

Resident, Ohod Hospital, Madinah (KSA)

Khalid Abdullah Alghamdi, MD

iikldxii@gmail.com

Fayez Dhyefallah Alghamdi, MD

fayezn96@gmail.com

Abdullah Faisal Al Muaibid, MD

almuaibid.96@gmail.com

Intern, Baha University, Baha (KSA)

Refal Ghassan Ajjaj, Student

refal.g@outlook.com

ISNC, Jeddah (KSA)

Seham Salem Almohammadi, MD

seham92.sm@gmail.com

Sarah Salem Almohammadi, MD

saroon.sml@gmail.com

Intern, KFH, Jeddah (KSA)

Wajd Adnan Alfitni, MD

wajd.alfattani@hotmail.com

Intern, Batterjee Medical College, Jeddah (KSA)

Abdulrahman Mohamed Homsi, MD

abdurrahman.homsi@gmail.com

Intern, Uqu University, Mecca (KSA)

Meqbel Majed Alshelawi, MD

1.10.m@hotmail.com

Intern, Medical University of Silesia, Katowice (Poland)

Hassan Ali Alshamrani, MD

h.alshomrani1416@gmail.com

Intern, Taif University, Taif (KSA)

Abdulrauf Abdulatif Tashkandi, MD

abdulrauf.t@hotmail.com

Intern, Taif University, Taif (KSA)

Sara Mohammed Mannan, Medical Student

King Abdulaziz university, Jeddah (KSA)

Salihah Attiah Alsamiri, Medical Student

s.at.alsamiri@gmail.com

RCSI, Dublin (Ireland) 